\title{
Effects of Cadmium, Lead, Manganese, and Zinc at WHO Safe Limits in Drinking Water on the in Vitro Availability of Chloramphenicol
}

\author{
${ }^{1} A$. Musa and *2I. Nasir. \\ 1Department of Pharmaceutical and Medicinal Chemistry, Faculty of Pharmaceutical Sciences, \\ Ahmadu Bello University, Zaria, Nigeria. \\ 2Department of Pharmaceutical and Medicinal Chemistry, Faculty of Pharmaceutical Sciences, \\ Usmanu Danfodiyo University, Sokoto, Nigeria. \\ [ ${ }^{\star}$ Corresponding author; email: thenasir25@gmail.com]
}

\begin{abstract}
In the present study, The in vitro availability of chloramphenicol was studied in the presence of lead $(\mathrm{Pb})$, cadmium $(\mathrm{Cd})$, manganese $(\mathrm{Mn})$ and zinc $(\mathrm{Zn})$ at $0.01,0.003,0.5$ and $3 \mathrm{mg} / \mathrm{L}$ respectively corresponding to WHO safe limits in drinking water for each of the metals. The in vitro availability study was carried out in simulated gastric juice $(0.1 \mathrm{M} \mathrm{HCl})$ and intestinal $\mathrm{pH}$ (phosphate buffer $\mathrm{pH} 9.0)$ at $37^{\circ} \mathrm{C}$ using a dissolution apparatus. Samples were taken at 15 minutes intervals over a period of 3 hours and analyzed for concentration of chloramphenicol available using a Helios Zeta Model 164617 UV/VIS spectrophotometer at 278nm. In simulated gastric juice, a maximum availability of $99.48 \%$ was achieved for chloramphenicol alone, while 89.48, 93.48, 105.88 and $93.60 \%$ of the drug was detected in the presence of $\mathrm{Cd}, \mathrm{Mn}, \mathrm{Pb}$, and $\mathrm{Zn}$ respectively. The corresponding maximum availabilities in simulated intestinal $\mathrm{pH}$ were 64.12 for chloramphenicol alone, and 64.36, $83.76,80.72$ and $64.96 \%$ in the presence of $\mathrm{Cd}, \mathrm{Mn}, \mathrm{Pb}$, and $\mathrm{Zn}$ respectively. The presence of $\mathrm{Cd}$ did not affect the overall availability of chloramphenicol in both media; while the availability of the drug was observed to increase slightly in the presence of $\mathrm{Pb}$ in both media. In simulated gastric juice, $\mathrm{Mn}$ and $\mathrm{Zn}$ did not affect the availability of chloramphenicol. However, their presence slightly increased the availability of the drug in simulated intestinal $\mathrm{pH}$. The results of this study indicate that the absorption and subsequent bioavailability of chloramphenicol may not be reduced by $\mathrm{Cd}, \mathrm{Pb}, \mathrm{Mn}$, and $\mathrm{Zn}$ at concentrations corresponding to WHO safe limits in drinking water. Bioavailability may even be enhanced especially in the intestine, which may result in therapeutic effectiveness.

Key words: Chloramphenicol, metal cations, in vitro availability
\end{abstract}

\section{INTRODUCTION}

Chloramphenicol, 2,2-Dichloro-N-[(a R, $\beta$ R)- $\beta$-hydroxya-hydroxymethyl-4-nitrophenethyl] acetamide, is a broad spectrum bacteriostatic antibiotic against a wide range of Gram-negative and Gram-positive organisms as well as other organisms, but at higher concentrations or against some very susceptible organisms it can be bactericidal (Sweetman, 2002). It is used in treatment of human infections with Salmonella typhi, and other forms of salmonellosis, and other life-threatening infections of central nervous system and respiratory tract (Parfitt, 1999). Its ability to cause aplastic anaemia and resistance has limited the use of the drug. However, it is still widely used in low-income countries (including Nigeria) because of its cheapness (Sweetman, 2002).

The availability of Chloramphenicol was reported to be significantly reduced when the drug was interacted with cadmium and lead in simulated gastric and intestinal $\mathrm{pH}$ at stoichiometric ratio of 2:1 (Musa et al., 2010). Interaction studies of ofloxacin with metal ions results in decrease bioavailability of ofloxacin (Sultana et al.,
2007). Availability of levofloxacin was reported to significantly decrease when the drug was interacted with several metals including $\mathrm{Cd}, \mathrm{Mn}$ and $\mathrm{Zn}$ (Sultana et al., 2004). Some antacids have been reported to significantly retard the availability of glibenclamide (Arayne et al., 2004).

As a result of such interactions, the absorption and consequent bioavailability of different drugs especially antibiotics may be significantly affected. Heavy metals commonly contaminate the environment and drinking water sources (Musa et al., 2008). The WHO safe limits for $\mathrm{Cd}, \mathrm{Pb}, \mathrm{Mn}$ and $\mathrm{Zn}$ in drinking water are $0.003,0.01$, 0.5 and $3 \mathrm{mg} / \mathrm{L}$ respectively (WHO, 1993). These limits address the toxic effects of these metals. This research work was aimed at evaluating the effect of $\mathrm{Cd}, \mathrm{Pb}, \mathrm{Mn}$ and $\mathrm{Zn}$ at concentrations corresponding to the WHO limits on the availability of chloramphenicol in simulated gastric and intestinal $\mathrm{pH}$. 


\section{MATERIALS AND METHODS}

\section{Equipment and reagents}

All metal salts (i.e. Lead chloride, Manganese Chloride, Zinc Chloride, Cadmium chloride and Chromium trioxide) and chemicals used were of analytical grade. Standard chloramphenicol powder was obtained as gift from Doyin pharmacy Nigeria limited. Chloramphenicol capsules were products of Green field pharmacy (JIANGSU) Co. Ltd (Batch-04-5485). Potassium dihydrogen orthophosphate was BDH-Laboratory reagents. Dissolution studies were performed using an ERWEKA (GMBH) dissolution apparatus. A double scanning UV/VIS spectrophotometer (Helios Zeta, Model 164617) was used to monitor the drug content.

\section{Identification and assasy of Chloramphenicol}

Both the Chloramphenicol reference standard and Chloramphenicol capsules were identified and assayed using official methods (BP, 2002).

\section{Preparation of dissolution media}

Dissolution was carried out in simulated gastric juice (containing $0.1 \mathrm{M}$ hydrochloric acid) and intestinal $\mathrm{pH}$ (phosphate buffer $\mathrm{pH}$ 9). Both media were prepared using official methods (BP 2002).

\section{Preparation of calibration curve}

Stock solutions $(1 \mathrm{mg} / \mathrm{ml})$ of Chloramphenicol reference standard were prepared in $0.1 \mathrm{M}$ hydrochloric acid and phosphate buffer $\mathrm{pH}$ 9. The absorbance of a $50 \mu \mathrm{g} / \mathrm{ml}$ solution was measured in the range of $200-350 \mathrm{~nm}$, which showed maxima at $278 \mathrm{~nm}$. Successive serial dilutions of the stock were done to obtain standard solutions of concentrations 10,20,30, 40 and $50 \mu \mathrm{g} / \mathrm{ml}$. The absorbance of each solution was measured at the maxima $(278 \mathrm{~nm})$. A plot of concentration against the corresponding absorbance was done in the case of each media. A straight line was obtained which obeyed the Beer-Lambert's law in each case. The Chloramphenicol contents in the two media during the in vitro availability studies were extrapolated from the calibration curves.

\section{Availability of Chloramphenicol}

The in vitro availability of Chloramphenicol in simulated gastric juice and intestinal $\mathrm{pH}$ at $37 \circ \mathrm{C}$ was determined using dissolution apparatus as outlined in BP (2002) with slight modification to the top of the basket in order to prevent air entrapment during dissolution. A capsule of chloramphenicol $(250 \mathrm{mg})$ was placed in the dissolution basket and allowed into the dissolution medium. The dissolution process was monitored over a period of 180 minutes, with aliquots $(10 \mathrm{ml})$ being withdrawn at 15 minutes intervals and assayed for drug content available. The volume of the dissolution medium was maintained after each withdrawal by an immediate replacement with $10 \mathrm{ml}$ of the dissolution medium maintained at the same temperature in the same bath.

For the in vitro availability of chloramphenicol in the presence of the metals, the drug was interacted with amounts equivalent to $0.01,0.003,0.5$ and $3.0 \mathrm{mg} / \mathrm{L}$ of lead, cadmium, manganese and zinc salts respectively in each dissolution media (1L) at concentrations corresponding to WHO safe limits for each of the metals in drinking water.. The process described above was then repeated to determine the drug content after each sampling.

\section{RESULTS}

The results of the identification test for both chloramphenicol reference standard and capsules revealed the presence of the active ingredient and the content assayed was within the official limits (98-105\%). For the qualitative determination of drug content, it was observed that the calibration curves of chloramphenicol in both simulated gastric juice (0.1M hydrochloric acid) and intestinal $\mathrm{pH}$ (Phosphate buffer pH9) at 278nm obeyed the Beer-Lambert's Law. The linear relationship between absorbance $(A)$ and concentration $(C$ in $\%$ w/v) is given by the regression equation $A=0.030 C+0.003$ and $A=0.033 \mathrm{C}+0.002$ for chloramphenicol in $0.1 \mathrm{M}$ hydrochloric acid and phosphate buffer $\mathrm{pH} 9$ respectively. The coefficient of correlation ( $r$ ) in each case is 0.999 . The calculated molar absorbtivities were $1,061 \pm 0.0004 \mathrm{M}^{-1} \mathrm{~cm}^{-1}$ and $1,123 \pm 0.0003 \mathrm{M}^{-1} \mathrm{~cm}^{-1}$ for $0.1 \mathrm{M}$ hydrochloric acid and phosphate buffer $\mathrm{pH} 9$ respectively.

The results of the in vitro availability of chloramphenicol at different time intervals in simulated gastric juice and intestinal $\mathrm{pH}$ at $37 \mathrm{O}^{\circ} \mathrm{C}$ alone and in the presence of $\mathrm{Cd}$, $\mathrm{Mn}, \mathrm{Pb}$, and $\mathrm{Zn}$ in their concentration corresponding to WHO safe limits in drinking water are shown in Tables 1 and 2. 
Nigerian Journal of Basic and Applied Science (March-June, 2014), 22(1\&2): 47-50

Table 1: Availability of Chloramphenicol at Different Time Intervals in Simulated Gastric Juice at 37॰C

\begin{tabular}{cccccc}
\hline Time $(\mathbf{m i n})$ & $\begin{array}{c}\text { Cpc } \\
\text { (\% Conc) }\end{array}$ & $\begin{array}{c}\text { Cpc + Cd } \\
\text { (\% Conc.) }\end{array}$ & $\begin{array}{c}\text { Cpc }+ \text { Mn } \\
\text { (\% Conc.) }\end{array}$ & $\begin{array}{c}\text { Cpc + Pb } \\
\text { (\% Conc.) }\end{array}$ & $\begin{array}{c}\text { Cpc + Zn } \\
\text { (\% Conc.) }\end{array}$ \\
\hline $\mathbf{1 5}$ & 70.28 & 74.52 & 76.92 & 95.20 & 78.12 \\
$\mathbf{3 0}$ & 87.20 & 85.88 & 89.60 & 95.08 & 88.12 \\
$\mathbf{4 5}$ & 88.80 & 89.48 & 91.20 & 97.32 & 92.80 \\
$\mathbf{6 0}$ & 91.60 & 88.80 & 93.60 & 94.28 & 93.60 \\
$\mathbf{7 5}$ & 90.52 & 88.68 & 91.48 & 105.88 & 92.80 \\
$\mathbf{9 0}$ & 90.00 & 89.48 & 90.68 & 97.20 & 92.52 \\
$\mathbf{1 0 5}$ & 90.52 & 88.40 & 92.00 & 91.08 & 91.72 \\
$\mathbf{1 2 0}$ & 90.12 & 87.60 & 90.52 & 93.32 & 91.20 \\
$\mathbf{1 3 5}$ & 88.52 & 85.72 & 90.92 & 95.08 & 91.60 \\
$\mathbf{1 5 0}$ & 99.48 & 87.32 & 88.48 & 90.92 & 90.40 \\
$\mathbf{1 6 5}$ & 90.52 & 85.60 & 89.60 & 89.48 & 88.28 \\
$\mathbf{1 8 0}$ & 87.88 & 85.48 & 93.48 & 90.00 & 89.48 \\
\hline
\end{tabular}

Table 2: Availability of Chloramphenicol at Different Time Intervals in Simulated Intestinal pH at 37॰C

\begin{tabular}{cccccc}
\hline Time $(\min )$ & $\begin{array}{c}\text { Cpc } \\
\text { (\% Conc) }\end{array}$ & $\begin{array}{c}\text { Cpc }+ \text { Cd } \\
\text { (\% Conc.) }\end{array}$ & $\begin{array}{c}\text { Cpc }+M n \\
(\% \text { Conc.) }\end{array}$ & $\begin{array}{c}\text { Cpc + Pb } \\
\text { (\% Conc.) }\end{array}$ & $\begin{array}{c}\text { Cpc + Zn } \\
\text { (\% Conc.) }\end{array}$ \\
\hline 15 & 56.60 & 20.84 & 62.20 & 3.40 & 34.44 \\
30 & 38.44 & 38.80 & 74.92 & 58.68 & 58.08 \\
45 & 54.80 & 54.80 & 80.72 & 72.48 & 63.88 \\
60 & 83.88 & 62.08 & 80.72 & 81.20 & 64.48 \\
75 & 60.24 & 59.64 & 79.52 & 83.28 & 63.04 \\
90 & 61.32 & 59.04 & 80.12 & 83.64 & 64.24 \\
105 & 60.12 & 59.52 & 78.80 & 83.76 & 64.96 \\
120 & 62.20 & 63.76 & 77.20 & 82.08 & 64.36 \\
135 & 59.88 & 56.60 & 78.80 & 81.32 & 62.22 \\
150 & 60.00 & 55.04 & 76.72 & 81.80 & 60.24 \\
165 & 57.92 & 64.36 & 75.18 & 80.12 & 59.04 \\
180 & 64.12 & 54.32 & 74.32 & 79.28 & 62.08 \\
\hline
\end{tabular}

\section{DISCUSSION}

In simulated gastric juice at $37 \circ \mathrm{C}$ chloramphenicol achieved a maximum availability of $99.48 \%(248.70 \mathrm{mg} / \mathrm{l})$ alone and respective maximum availabilities of $89.48 \%$, $93.60 \%, 105.88 \%$ and $93.60 \%(223.70,234.00,264.70$ and $234.00 \mathrm{mg} / \mathrm{l})$ in the presence of $\mathrm{Cd}, \mathrm{Mn}, \mathrm{Pb}$ and $\mathrm{Zn}$. Presence of $\mathrm{Cd}$, Mn and $\mathrm{Zn}$ did not affect the availability of chloramphenicol, while the availability of the drug was increased in the presence of $\mathrm{Pb}$. The increase in concentration of the drug in this study is contrary to what was reported by Musa et al. (2010), also in the in vitro availability and interaction studies of ciprofloxacin, Levofloxacin and ofloxacin in the presence of some metals including $\mathrm{Cd}, \mathrm{Mn}, \mathrm{Pb}$ and $\mathrm{Zn}$. The little reduction in drug content in the presence of $\mathrm{Cd}, \mathrm{Mn}$ and $\mathrm{Zn}$ in simulated gastric juice may be because the complexation of certain drugs by polyvalent cations is not favoured in acid medium (Sanchez et al., 1994) and also the low concentrations of the metal cations used in this study.

In simulated intestinal $\mathrm{pH}$, chloramphenicol alone achieved a maximum availability of $64.12 \%$ $(160.30 \mathrm{mg} / \mathrm{l})$ at $30 \circ \mathrm{C}$. The maximum availabilities of $64.36 \%, 83.76 \%, 80.72 \%$ and $64.96 \%$ (160.90, 209.40, 201.80 and $162.40 \mathrm{mg} / \mathrm{l}$ ) were obtained in the presence of $\mathrm{Cd}, \mathrm{Mn}, \mathrm{Pb}$ and $\mathrm{Zn}$ respectively. Presence of $\mathrm{Cd}$ did not affect the maximum availability of chloramphenicol. However, the presence of $\mathrm{Mn}, \mathrm{Pb}$ and $\mathrm{Zn}$ increased the overall maximum availability of chloramphenicol. 
It is evident from the results that $\mathrm{Cd}$ did not affect the overall observed maximum availability of chloramphenicol in both media whereas presence of $\mathrm{Pb}$ increased the availability of the drug in both media. In simulated gastric juice, $\mathrm{Mn}$ and $\mathrm{Zn}$ did not affect the availability of the drug however their presence increased the availability of the drug in simulated intestinal $\mathrm{pH}$. The fact that there are reports suggesting dissolution rate of certain antibiotics is markedly reduced at high $\mathrm{pH}$ values (Sultana et al., 1984)., a similar trend was also reported where the availability of levofloxacin was markedly reduced in the presence of different metals (including $\mathrm{Cd}, \mathrm{Mn}$ and $\mathrm{Zn}$ ) in a medium of $\mathrm{pH} 9$ at $37 \circ \mathrm{C}$ (Sultana et al., 2004), in the present study a different pattern emerged as increase in the availability of Chloramphenicol was observed in the presence of $\mathrm{Cd}$, $\mathrm{Pb}, \mathrm{Mn}$ and $\mathrm{Zn}$ in both media which was more pronounced in intestinal $\mathrm{pH}$. This may be attributed to the fact that WHO safe limits of the metals was used in this study while other studies that reported significant decrease in availability of drug used relatively higher concentrations of metals (Sultana et al., 2004; Sultana et al., 2007; Musa et al., 2010).

\section{CONCLUSION AND RECOMMENDATIONS}

From the results obtained, it can be concluded that the absorption and subsequent bioavailability of chloramphenicol may not be reduced by $\mathrm{Cd}, \mathrm{Mn}, \mathrm{Pb}$ and $\mathrm{Zn}$ metals at concentrations corresponding to $\mathrm{WHO}$ safe limits for each of the metals in drinking water. Bioavailability of drug may even be enhanced and this effect was observed to be more pronounced in the simulated intestinal $\mathrm{pH}$ than in simulated gastric juice which may result in therapeutic effectiveness. Furthermore, the $\mathrm{pH}$ of a medium is an important factor in the dissolution and subsequent availability of drugs as observed in this study. Drinking water should be treated to ensure the concentrations of these heavy metals are within the WHO safe limits as these limits have been shown to be adequate with respect to interaction with chloramphenicol. Further studies on the effect of actual concentrations of these metals found as contaminant in drug and food should be evaluated.

\section{REFERENCES}

Arayne, M.S, Sultana, N and Kamran Zaman, R.M. (2004) In Vitro Availability of Glibenclamide in Presence of Antacids. Pakistan Journal of Pharmaceutical. Sciences, 17 (2): 41-56

British Pharmacopoeia (2002) Vol II. Printed for Her Majesty's Stationary office at University Press, Cambridge, Appendix VII.

Musa A., Yakasai, I.A., M Garba and B.K Mathias. (2010). Invitro availability of chloramphenicol in the presence of lead and cadmium salts. Journal of Basic and Clinical Pharmacy, 1(2): 97-101.

Musa, A, Yakasai, I. A and Ya'u, I. B (2008): The concentrations of lead in shallow Well, Borehole and package water samples in Zaria, Nigeria. International Journal of Pure and Applied Science, 2(2):

Parfitt, K. (1999) Martindale: The Complete Drug Reference $32^{\text {nd }}$ Ed., London: Pharmaceutical Press, pp.182-184.

Sanchez, B.M., Cabarga, A.S., Navario, A.S and Hurle, A.D. (1994). A Physicochemical study of the Interaction of Ciprofloxacin and Ofloxacin with Polyvalent Cations. International Journal of Pharmaceutics, 106: 229-235.

Sultana, N., Arayne, M.S. and Sharif, S. (2004). Levofloxacin Interactions with Essential and Trace Elements. Pakistan Journal of Pharmaceutical Sciences, 17(2): 67-76.

Sultana, N., Arayne, M.S. and Ghazali, F.A. (1984). Effects of Antacids on the Dissolution Behaviour of Methacycline and Doxycycline. Journal of Pakistan Medical Association, 34 (3): 59-63.

Sultana, N., Arayne, M.S And Yasmeen, N. (2007). In vitro availability of ofloxacin in presence of metals essential to human body. Pakistan Journal of Pharmaceutical Sciences, 20(1): 36-42.

Sweetman, S.C. (2002). Martindale. The complete drug reference $35^{\text {th }}$ edition: The Royal pharmaceutical society of Great Britain, London. Electronic version

World Health Organisation (WHO), (1993). Guidelines for Drinking Water Quality Vol 1 Recommendations. France. WHO 181p. ISBN 924-154460D 